\title{
The validity and value of revalidation
}

\author{
Stephen Hancocks OBE \\ Editor-in-Chief
}

The General Dental Council's (GDC) consultation on revalidation for dentists closed on 6 January 2011 and so I can imagine that your immediate reaction might be, 'so why is he telling us this when it is too late to comment?' Well, firstly we did give adequate notice had you wished to respond and secondly it is more to ruminate on the matter in the light of the BDA's robust response on behalf of the profession and where the proposals might go from here.

Revalidation is another of the areas, rather like infection control procedures, which everyone agrees is vital, necessary, a safeguard, in the public interest and so forth and so on BUT, in order to be workable needs to be 'proportionate to the problem it wishes to address' to quote from the BDA's response. ${ }^{1}$ We are variously in the midst of HTM 01-05, Care Quality Commission registration and other regulatory tizzies that are costly, burdensome and frankly questionable in relation to their proportionality to the problems they seek to solve. The spectre of another bureaucratic juggernaut heading towards us is too exhausting to contemplate. To some extent then, I believe we can take heart. Two immediate issues have started to muddy the water; firstly, the government has indicated that it intends to consult further in 2011 about regulation of the professions, which could lead to a complete review of the current revalidation proposals. Secondly the GDC itself, taking cognisance of the BDA's earlier request, is to undertake a costrisk-benefit analysis as a priority. All of which suggests that any revalidation process would not come into effect until 2015 at the earliest and, given that the current proposals are to link it with continuing professional development (CPD) cycles, it would then be at least 2020 before any heads began to roll.

\section{CONSULTATION WOULD HAVE BEEN BETTER WITHDRAWN}

Not that this information in itself means that we can take our attention off the subject. The wheels of government and regulation may turn slowly but without continual monitoring and input they can change both direction and gearing before they next appear shining with unnerving alterations in a new dawn. Although the BDA's response is based on the current consultation document, despite the likelihood of change and in the Association's belief that the consultation would have been better withdrawn until the two reviews outlined above have been completed, it is also with an eye to the middle distance.

One of the major proposals that the BDA views as being onerous and bureaucratic is that of third-party verification. Under the proposals there would be a three-stage process. The first is a compliance check, the second a remediation and the third an in-depth assessment against standards. Each of these would require a standards and evidence framework setting out the standards dentists must meet under the four domains of clinical, management and leadership, communication and professionalism, each domain being of equal importance. The framework would also set out the evidence which will be acceptable to demonstrate compliance with each standard. ${ }^{2}$

Requiring third-party verification of evidence from stage one upwards is not itself 'based on evidence of need and is inappropriate in the current economic climate' according to the Association's response, proposing instead that a system of self- and peer review would be proportionate and effective. As I have written here before, 'such degrees of scrutiny involve not only an increasing reliance on judgment, which is expensive, but also a raft of other resources, all of which involve time and all of which cost resources and ultimately money. ${ }^{3}$

Added to which has to be the over-riding question of need from the public's perspective. Of course they (and we, when we are patients ourselves) rightly expect competence in those who provide care and treatment but there are also expectations of reasonable access and affordability both of which are in danger of being jeopardised by the furtherance of another potential layer of regulation, some of which would duplicate existing systems. Again, as the Association points out, there is a danger that so many safeguards will actually reduce the amount time available for the delivery of dental care. Additionally, the enormous cost implications of the current proposals may cause increasing numbers of dentists to retire earlier than they might have done otherwise. This might also be a consideration for dentists on career breaks, older dentists and those with limited and/or part-time practice.

The GDC continues to make great play of the rise in the number of fitness to practice cases but an audit to assess how many such hearings might be reduced as a result of the proposed revalidation processes would surely be another important preliminary step. Overall, the message seems to be that there is a long way to go on this aspect of future practice to establish both the value and validity of revalidation. $\mathrm{Oh}$, and as a last thought, this is so far just for dentists - wait until the dental care professionals become involved.

1. BDA. British Dental Association response to the General dental Council's consultation on revalidation. London: BDA, 2011. http://www.bda.org/Images/ bda_response_to_revalidation_consultation_january_2011_-_final.pdf

2. GDC. Revalidation for dentists. Our proposals. London: GDC, 2010. www.gdc-uk.org 3. Hancocks S. Revalidating a Merry Christmas. Br Dent J 2008; 205: 635.

DOI: $10.1038 / \mathrm{sj}$. bdj.2011.5 